\title{
A prospective clinical study on implant impression accuracy
}

\author{
Motaz Osman ${ }^{1}$, Hassan Ziada ${ }^{2}$, Ahmed Suliman ${ }^{3}$ and Neamat Hassan Abubakr ${ }^{4^{*}}$ (D)
}

\begin{abstract}
Background: An accurate impression is crucial to the long-term success of dental implants. This investigation evaluated the accuracy of the open and closed implant impression techniques in partially edentulous patients who received two adjacent implants.

Material and methods: Forty patients received Osstem Implants (Osstem Implant System, Seoul, Korea). Two impressions were made for each patient, one using an open tray and a second with a closed tray technique. The horizontal distances between two impression copings were measured and compared to similar measurements on the master casts. Also, under a stereomicroscope (AmScop14370, Myford Road, \#150, Irvine, CA 92606 USA) at a 50-fold magnification, the presence or absence of the marginal discrepancies was evaluated.

Results: There were no statistically significant differences regarding horizontal measurements and in the marginal relationship for the two impression techniques, except between the anterior and posterior regions, for the closed tray technique. There were also no statistically significant differences in the impression accuracy between maxillary and the mandibular arches. In addition, there were no statistically significant differences for the intraoral horizontal distances, compared to similar horizontal measurements on master casts, between the open and closed tray techniques.
\end{abstract}

Conclusions: Within the limitations of the present study, there were generally no differences in the impression accuracy between the open and closed tray techniques in partially edentulous patients with two adjacent implants.

Keywords: Implant impression accuracy, Open tray technique, Closed tray technique, Marginal discrepancy

\section{Introduction}

Tooth loss reduces the masticatory ability, compromises esthetics, and may consequently diminish social interactions, which could significantly impact on the quality of life of individuals [1-3]. Treatment options for teeth loss are continuously evolving, from the removable prosthesis to the increasing preference for fixed choices. Furthermore, the progress in the manufacturing of titanium implants added to their long-term success, increasing the fixed prosthetic options for replacement of missing teeth, making implants an essential part of contemporary dental practice and a popular choice for both patients and clinicians [4].

An implant impression is primarily a three-dimensional record of the implant and the surrounding tissues. Impression accuracy is a significant factor in implant long-

\footnotetext{
* Correspondence: neamat.hassan@unlv.edu

${ }^{4}$ Biomedical Sciences, School of Dental Medicine, University of Nevada, Las Vegas, 1001 Shadow Lane, Suite 240, MS 7412, Las Vegas, NV 89106, USA
} Full list of author information is available at the end of the article term success. Inaccuracies or errors occurring at any stage of the superstructure construction may lead to a lack of precision fit between various components. The lack of potential compensatory readjustment, due to the absence of intervening periodontal ligament, may have the consequence of related complications or failure $[5,6]$.

The fit of an implant superstructure is considered "passive" if it does not create or lead to any static loading within the prosthesis, or in the surrounding bone. Imperfections in the precision fit may increase the incidence of mechanical problems or abutment loosening as well as possible fracture of the prosthetic or implant components. Furthermore, any resultant marginal discrepancies as a consequence of inaccurate impressions may enhance plaque accumulation, which would impact negatively on the soft and hard tissues around the implant [7].

The research on implant impression accuracy is mostly from in vitro studies, and the limited number of clinical 
studies might be contributing to the controversy as to which technique should be considered to be more superior $[5,8]$. We hypothesize that clinically, there is no impact or differences in impression accuracy.

This study aimed to evaluate the accuracy of the open and closed implant impression techniques in partially edentulous patients with two adjacent implants.

\section{Materials and methods}

The current study was conducted to investigate the accuracy of the open and closed implant impression techniques in partially edentulous patients with two adjacent implants. The ethical principles were adhered to, and ethical approval to conduct the study was duly obtained from the Ministry of Health, State Khartoum, Khartoum University Teaching Hospital, number: [WK/OS/ AETEA/44/1].

Patients who were scheduled to receive two adjacent implants were invited to participate in the study. The sample that would have sufficient power for analysis was calculated based on data from the previous clinical study by Stimmelmayr in 2013 [9]. The sample size was determined using the following formula:

$$
n=\frac{(z \sigma)^{2}}{(d)^{2}}
$$

where:

$n=$ the required sample size

$Z=$ is the critical value of the normal distribution

$\sigma=$ the standard deviation taken from the previous study

$d=$ the margin of error $(10 \% \times$ mean $)$.

The sample size was 31 patients; this was increased to 40 participants to accommodate patient dropouts during the study.

The inclusion criteria were patients over 18 years of age and willing to participate. A prerequisite to participation was a treatment plan that would involve two adjacent implants. The patient should also be category ASA I or ASA II medical history (American Society of Anesthesiologists Classification) [10]. Furthermore, evidence of bone loss or implant mobility at the time of impression making, formed part of the exclusion criteria $[11,12]$.

Informed consent was made, and participants who agreed to participate signed the consent form. For every patient, a surgical positioning guide was fabricated from a diagnostic wax-up that correlated the anatomic conditions. The implant (Osstem Implant System, Seoul, Korea) installation directions were carried out according to the amount and status of the available bone [13]. A Specialist Oral Surgeon placed the implants using the manufacturer's standardized

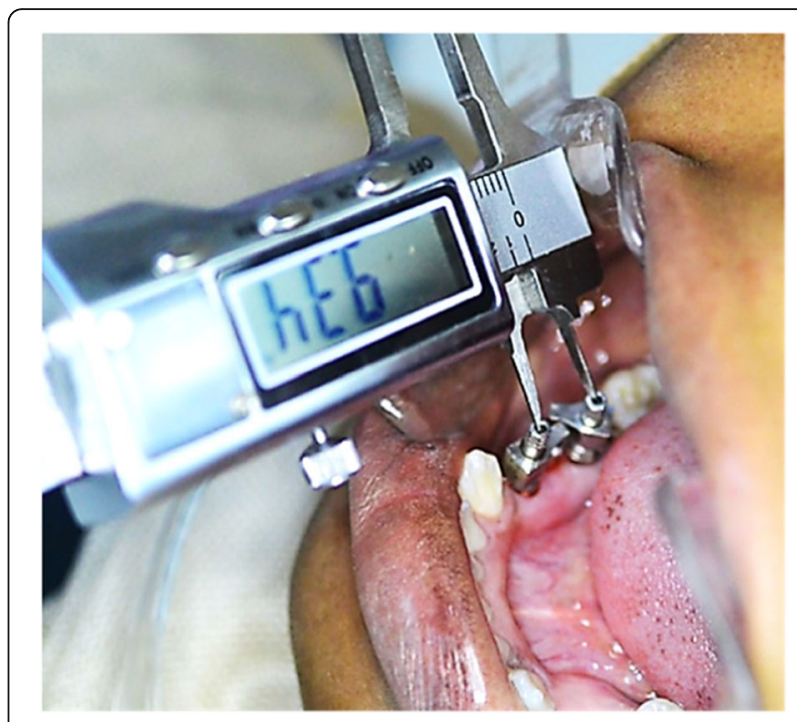

Fig. 1 Horizontal measurements between the two impression copings in the patient's mouth

technique, and similarly, a Specialist Prosthodontist carried out the related restoration steps. For making the impressions, individual trays were initially checked intraorally, and the final impressions made using Virtual Monophase vinyl polysiloxane impression material (Ivoclar Vivadent AG). Before impression making, the horizontal distance between the two impression copings was measured inside the patient's mouth using a digital caliper (HSL 246-15, Karl Hammacher GmbH, Germany) and recorded (Fig. 1). This recorded intraoral horizontal distances would later be compared against similar horizontal measurements on the master casts, to evaluate discrepancies or horizontal displacements between the positions intraorally and on the master casts. The same impression evaluation criteria used in our previous study

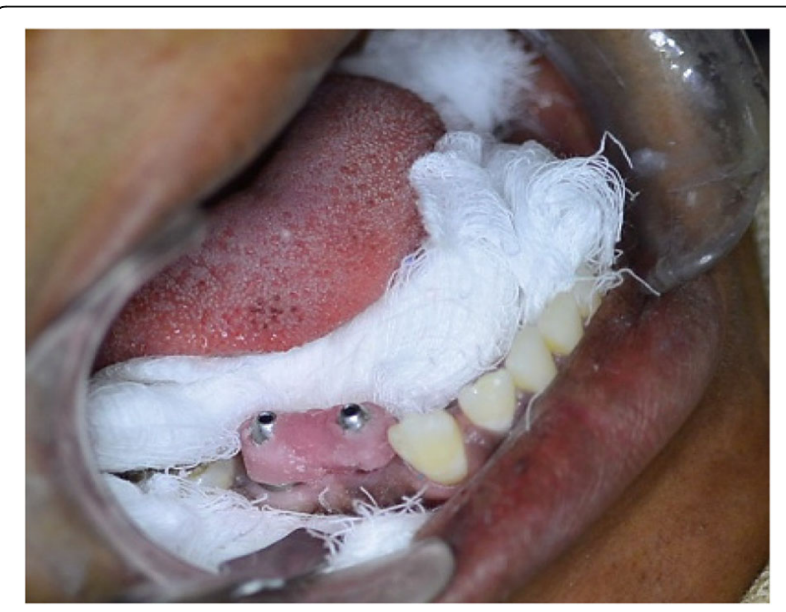

Fig. 2 Light cure acrylic resin verification jig in the patient's mouth 


\section{Maxilla Mandible Anterior Posterior}

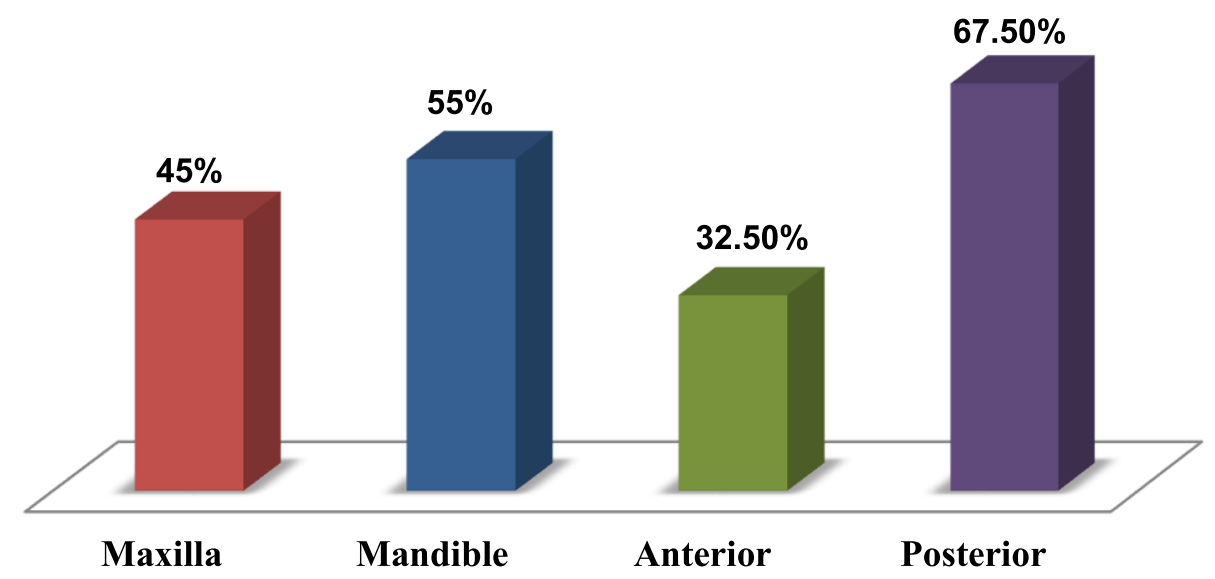

Fig. 3 Sample distribution according to arch and position

were also used here [8], which was described by Lee and Gallucci as follows [14]:

1. There should be accurate imprints of the implant areas.

2. There should be no voids in the occlusal, buccal, lingual, and interproximal surfaces of the neighboring teeth.

3. There should be a proper reproduction of the implant area.

4. There should be no impression material in the analog-impression coping interfaces.

5. The impression material should not be separated from the custom tray.

6. The transfer copings should not be displaced from the impression.

Any impression not meeting these criteria was repeated until the criteria were met. Two impressions were made for every patient by the same clinician, one using the open and a second with the closed tray technique.

For the analysis of accuracy in the vertical direction or marginal discrepancy, verification jigs were constructed to connect the two impression copings [15]. These verification jigs were used to transfer the relationships between the two impression copings and their implants from the patients' mouths to the master casts. To construct the verification jig, the two impression copings would be attached to their implant, inside the patient mouth, and a string of dental floss is wrapped around to connect the two impression copings (Fig. 2). A light cure acrylic resin (Al dente dental products $\mathrm{GmbH}$, Germany) adapted over the dental floss in increments and cured according to the manufacturer's instructions. The impression coping's screws would then be loosened, and the jig removed [16].

The impression copings for both the open and closed tray techniques were re-assembled and fixed into their corresponding implant analogs. Dental Stone Type IV (Elite Rock, Zhermack) was mixed using a vacuum machine for $30 \mathrm{~s}$, then poured using the boxing technique over a vibrator, and the casts separated after $45 \mathrm{~min}$ according to the manufacturer's instruction [17, 18]. The master casts were then sectioned to a base of $20 \mathrm{~mm}$, to allow their allocation under the stereomicroscope (AmScop14370, Myford Road, \#150, Irvine, CA 92606 USA), to be examined at a $\times 50$ magnification, and to evaluate the presence or absence of marginal discrepancy $[8,19]$.

Two examiners were involved in the evaluations, and inter-examiner reliability of 0.932 was obtained.

\section{Statistical analysis}

All the data were tabulated and statistically analyzed using IBM SPSS Statistics software version 22. The $t$ test was used to compare intraoral and master cast horizontal distances as well as sub-groups of the open and close impression tray techniques. Where data are not normally distributed, Wilcoxon signed test was used for numerical

Table 1 The $t$ test for horizontal measurements of the intraoral and master cast in the open and closed tray techniques

\begin{tabular}{llllllll}
\hline $\begin{array}{l}\text { Impression } \\
\text { technique }\end{array}$ & $N$ & Mean & $\begin{array}{l}\text { Std. } \\
\text { deviation }\end{array}$ & $\begin{array}{l}\text { Std. error } \\
\text { mean }\end{array}$ & P value \\
\hline Intraoral & Open & 40 & 9.327 & 3.356 & 0.531 & 0.205 & 0.838 \\
& Closed & 40 & 9.181 & 2.974 & 0.470 & & \\
$\begin{array}{l}\text { Master } \\
\text { cast }\end{array}$ & Open & 40 & 9.359 & 3.376 & 0.534 & 0.188 & 0.851 \\
& Closed & 40 & 9.225 & 2.970 & 0.470 & & \\
\hline
\end{tabular}

Significance level $p \leq 0.05$ 


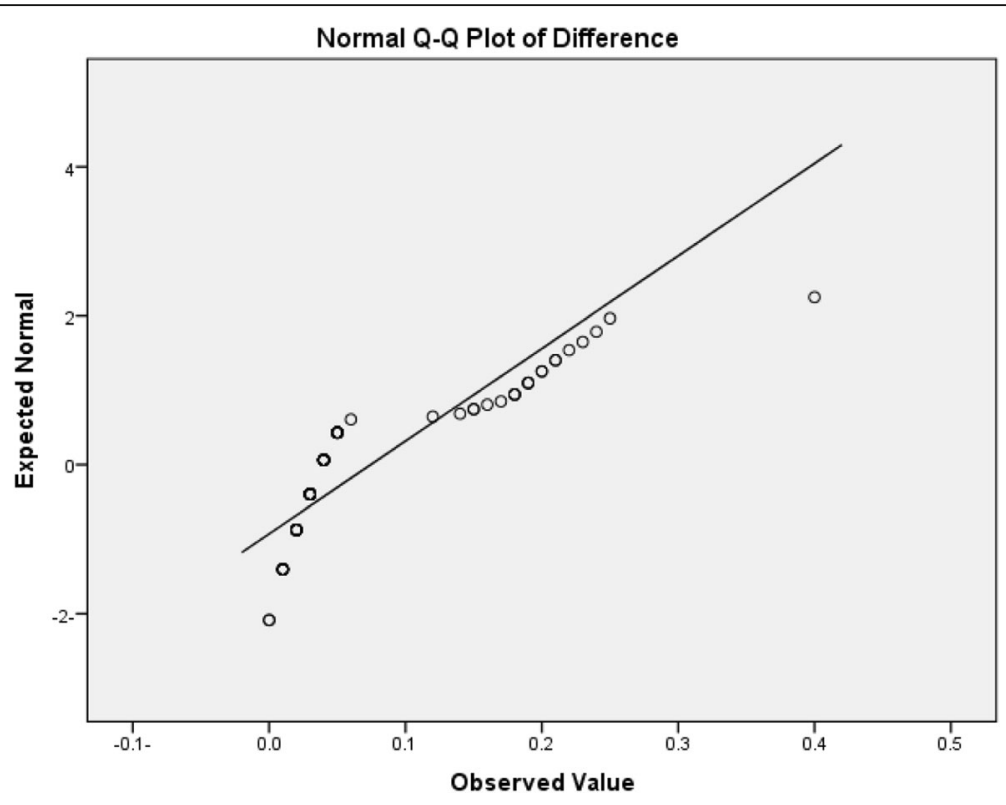

Fig. 4 Normality line of the distribution horizontal measurement data for the intraoral and working casts

dependent data and paired data; Mann-Whitney $U$ test was used for independent numerical groups. Chi-square test was used for the association between categorical variables. The $p$ value was set at $p \leq 0.05$ and regarded as statistically significant.

\section{Results}

Eighty impressions were made for 40 patients, using the open, then the closed impression techniques. There were 18 impressions in the maxillary and 22 in the mandibular arch; of these, 13 were in the anterior and 27 in the posterior region (Fig. 3).

A $t$ test indicated no statistically significant difference between the open and closed tray techniques for intraoral horizontal measurements against the similar horizontal measurements on the master casts (Table 1). A normality line test, for intraoral and master casts readings (horizontal measurements), revealed that they were not normally distributed (Fig. 4).

The Wilcoxon signed-rank test revealed that there are no statistically significant differences between the open and closed tray implant impression techniques (Table 2). The Mann-Whitney $U$ test also showed no statistically significant differences for maxillary and mandibular

Table 2 Open and closed tray techniques accuracy using the Wilcoxon signed-rank test

\begin{tabular}{llllll}
\hline Techniques & Number of impressions & Median & Mean & SD & $P$ value \\
\hline Open tray & 40 & 0.040 & 0.03230 & 0.0663 & 0.365 \\
Closed tray & 40 & 0.040 & 0.0437 & 0.918 & \\
\hline
\end{tabular}

Significance level $p \leq 0.05$ impressions in both the open and closed tray techniques (Table 3).

The Mann-Whitney $U$ test evaluated impression accuracy in the horizontal measurements according to the arch. There were no statistically significant differences between maxillary and mandibular arches, for the open and closed tray technique (Table 4).

The Mann-Whitney $U$ test also showed no statistically significant difference in the horizontal measurement between the anterior and posterior regions for the open tray impression technique (Table 5). However, statistically significant differences were detected in the horizontal measurements, between the anterior and posterior regions in the closed tray impression technique (Table 4).

The marginal discrepancy evaluation and percentages by arch and region are presented in Fig. 5. The chisquare test associated marginal discrepancies between maxillary and mandibular, and anterior and posterior regions. There were no statistically significant differences in the marginal discrepancy between maxillary and mandibular arches, and anterior and posterior in both open and closed tray impression techniques (Table 6).

Table 3 Open and closed tray technique accuracy in the maxilla and mandible, using the Mann-Whitney $U$ test

\begin{tabular}{lllllll}
\hline Techniques & Variables & $\begin{array}{l}\text { Number of } \\
\text { impressions }\end{array}$ & Median & Mean & SD & $P$ value \\
\hline Open tray & Maxilla & 18 & 0.040 & 0.0833 & 0.076 & 0.107 \\
& Mandible & 22 & 0.030 & 0.0464 & 0.054 & \\
Closed tray & Maxilla & 18 & 0.040 & 0.0756 & 0.076 & 0.419 \\
& Mandible & 22 & 0.040 & 0.0945 & 0.0104 & \\
\hline
\end{tabular}

Significance level $p \leq 0.05$ 
Table 4 Impression technique accuracy in the anterior and posterior regions using the Mann-Whitney $U$ test

\begin{tabular}{lllllll}
\hline Techniques & Variables & $\begin{array}{l}\text { Number of } \\
\text { impressions }\end{array}$ & Median & Mean & SD & $P$ value \\
\hline Open tray & Anterior & 13 & 0.04 & 0.0569 & 0.0497 & 0.360 \\
& Posterior & 27 & 0.03 & 0.0659 & 0.0737 & \\
Closed tray & Anterior & 13 & 0.03 & 0.0515 & 0.0571 & $0.039^{*}$ \\
& Posterior & 27 & 0.04 & 0.1026 & 0.1013 & \\
\hline
\end{tabular}

*Significance level $p \leq 0.05$

\section{Discussion}

Impression accuracy at the implant level is believed to have a higher degree of accuracy, compared to abutmentlevel impressions [20]. However, studies reporting on impression accuracy in implant dentistry may vary, and there are several possible explanations for these variations. One reason is the splinting together of copings for pick-up impressions compared to the non-splinting of copings. Secondly, the edentulous spans evaluated may differ between studies; thirdly, marginal discrepancy evaluation may use magnifying visual assessment as in the current investigation, or a superimposition of digital models as in Stimmelmayr et al. [9]. One variant that might have an impact is the impression material used. In one study, the impression material had the most considerable effect size on accuracy in terms of the 3D shift, and the implant axis inclination [21].

Most of the data on implant impression accuracy is from in vitro studies, with a small number conducted in a clinical setting. The limited number of clinical studies was highlighted in a systemic review by Papaspyridakos et al., where from the 76 studies reviewed, only 4 were in a clinical setting [22]. Baig, also in a report on the accuracy of multiple implants impressions of edentulous arches, found only 3 of the 56 studies reviewed to be in a clinical setting [7]. Also, when the same author conducted a systematic review, only 1 study out of the 34 selected for the systematic review was a clinical study [23].

This prospective clinical investigation found no significant differences between open and closed tray techniques, in agreement with Gallucci et al. [24]. In our in vitro study, we also found that the open and closed tray implant impression techniques showed a similar level of accuracy [8]. In that study, all the impressions were in the posterior maxillary region, while the current study had variations of anterior, posterior, maxillary, and mandibular. However, the current study is in disagreement with Stimmelmayr et al., where they found that the splinted implants in the open tray were more accurate than that in the closed tray technique [9].

Regarding the influence on the accuracy of the implant position within the dental arch, the current study found that the implant position in the dental arch had no influence or impact on impression accuracy, similar to the report by Gallucci et al. [24]. However, and in contrast, Papaspyridakos et al. found that the position in the dental arch influenced accuracy [22]. However, the Papaspyridakos et al. study involved utilizing the open tray technique only and used splinted impression copings. Furthermore, polyether impression was the material used in their study, and accuracy evaluation was through superimposition of optical scans, and perhaps, these differences may have contributed to the variance in outcomes.

There is currently an increase in the use of digital impressions in dentistry. In a recent systematic review comparing digital and conventional impressions, out of 10 articles, 5 encouraged the use of intraoral scanners in the implant field, while two studies found that digital scanning is not reliable and could not be used in clinical practice. However, it is still early to conclude whether to use digital scanners in implant dentistry as standard procedure and further studies should clarify this issue [25].

The current study generally found no statistically significant differences in the marginal discrepancy between both impression techniques. This is contrary to the findings of Papaspyridakos et al., where statistically significant differences were found concerning marginal discrepancy between the groups studied [26].

Any stage of implant prosthesis fabrication may contribute to positional distortion or imprecision. Decreasing distortion factors in the horizontal and vertical

Table 5 The horizontal discrepancies according to implant position in the arch, using the Mann-Whitney $U$ test

\begin{tabular}{|c|c|c|c|c|c|c|c|c|c|}
\hline \multirow{2}{*}{$\begin{array}{l}\text { Horizontal } \\
\text { discrepancies }\end{array}$} & \multirow[t]{2}{*}{ Position } & \multirow[t]{2}{*}{$N$} & \multicolumn{3}{|c|}{ Open tray } & \multicolumn{3}{|c|}{ Closed tray } & \multirow{2}{*}{$\begin{array}{l}P \\
\text { value }\end{array}$} \\
\hline & & & Mean & Median & S.D & Mean & Median & S. D & \\
\hline \multirow[t]{3}{*}{ Maxilla } & Anterior & 9 & 0.069 & 0.040 & 0.055 & 0.047 & 0.020 & 0.050 & 0.110 \\
\hline & Posterior & 9 & 0.098 & 0.040 & 0.093 & 0.101 & 0.050 & 0.090 & 0.136 \\
\hline & Total & 18 & 0.084 & 0.040 & 0.075 & 0.075 & 0.035 & 0.070 & 0.584 \\
\hline \multirow[t]{3}{*}{ Mandible } & Anterior & 4 & 0.030 & 0.035 & 0.022 & 0.063 & 0.079 & 0.030 & 0.999 \\
\hline & Posterior & 18 & 0.050 & 0.030 & 0.059 & 0.102 & 0.109 & 0.045 & 0.118 \\
\hline & Total & 22 & 0.0464 & 0.04 & 0.054 & 0.095 & 0.104 & 0.040 & 0.152 \\
\hline
\end{tabular}

Significance level $p \leq 0.05$ 


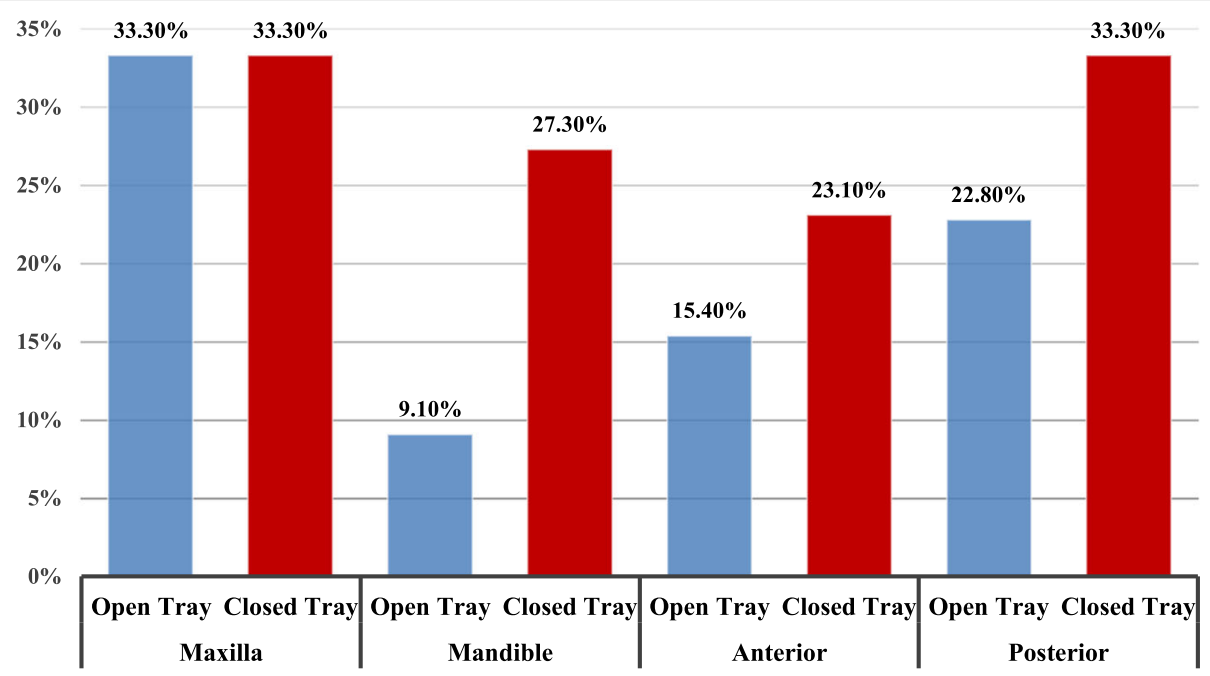

Fig. 5 Marginal discrepancy distribution in the open and closed techniques, maxillary mandibular, and anterior and posterior regions

dimensions may reduce the potential on impression misfits of the implant superstructures. Several methods may be used to evaluate the presence or absence of marginal discrepancy; in the current study, the one screw test with a verification jig was used, since it has been widely used to determine marginal discrepancies [15, 27-29].

One of the limitations of our study is the lack of matching arches and regions. This may have yielded variable data and would have perhaps influenced the outcomes of implant impression accuracy. Also, the exact position of the implant in relation to accuracy have not been considered in this study, and further studies should consider evaluating this.

A further limitation is that specialists undertook the management of the patients in this study, and it would have been interesting to evaluate the effect of clinical experience on impression accuracy, though that would have probably required a larger sample to obtain the appropriate power to assess these variables. A further limitation is the effect of implant angulations on the accuracy was not assessed in this study. Also, this study investigated impression accuracy in relationship to adjacent implants, and the results should be viewed regarding adjacent implants only, and that spaced and

Table 6 Chi-square test of marginal discrepancies for the impression techniques, by implant position in the arch

\begin{tabular}{llll}
\hline Marginal discrepancy & Open tray & Closed tray & $P$ value \\
\hline Maxilla & $6(33.3 \%)$ & $6(33.3 \%)$ & 0.999 \\
Mandible & $2(9.1 \%)$ & $6(27.3 \%)$ & 0.240 \\
Anterior & $2(15.4 \%)$ & $3(23.1 \%)$ & 0.50 \\
Posterior & $6(22.2 \%)$ & $9(33.3 \%)$ & 0.272 \\
\hline
\end{tabular}

Significance level $p \leq 0.05$ divergent implants would possibly yield different outcomes.

\section{Conclusion}

Within the limitation of this study, there were no differences in the impression accuracy between the open and closed tray techniques, in partially edentulous jaws with two adjacent implants. Also, there were no differences between the two impression techniques regarding marginal discrepancy. The position of the implant, in the maxilla or mandible, had no effect on the impression accuracy of both techniques.

\section{Acknowledgements}

The authors would like to acknowledge the statistical support provided by Dr. Abdlaal Fadol.

\section{Authors' contributions}

$\mathrm{MO}$ carried out the recruitment and impression making, measurements, data collection, and drafting of the manuscript. $\mathrm{HZ}$ performed the analysis and interpretation of data and participated in the drafting and preparing of the manuscript. AS participated in the design of the study and discussion of the results. NHA participated in the conception, design and analysis of the study, and participated in the preparation and revision of the manuscript. All authors read and approved the final manuscript.

\section{Funding}

No funding (not applicable).

\section{Availability of data and materials}

The authors declare that they have full control on all data and materials of this study.

\section{Ethics approval and consent to participate}

The ethical principles were adhered to, and ethical approvals to conduct the study were duly obtained from the Ethical Committee of the Ministry of Health, Khartoum State, Khartoum Teaching Dental Hospital, number: [WK OS/AETEA/44/1]

\section{Consent for publication}

All authors read and approved the final manuscript and consent to the publication. 


\section{Competing interests}

Motaz Osman, Hassan Ziada, Ahmed Suliman, and Neamat Abubakr Hassan declare that they have no competing interests.

\section{Author details}

'Department of Oral Rehabilitation, Faculty of Dentistry, University of Khartoum, Khartoum, Sudan. ${ }^{2}$ Clinical Sciences, School of Dental Medicine, University of Nevada, Las Vegas, NV, USA. ${ }^{3}$ Department of Oral Maxillofacial Surgery, University of Khartoum, Khartoum, Sudan. ${ }^{4}$ Biomedical Sciences, School of Dental Medicine, University of Nevada, Las Vegas, 1001 Shadow Lane, Suite 240, MS 7412, Las Vegas, NV 89106, USA.

Received: 1 April 2019 Accepted: 9 October 2019

Published online: 19 November 2019

\section{References}

1. Khalifa N, Allen PF, Abu-bakr NH, Abdel-Rahman ME. Factors associated with tooth loss and prosthodontic status among Sudanese adults. J Oral Sci. 2012;54:303-12.

2. Oliver RC, Brown LJ. Periodontal diseases and tooth loss. Periodontol 2000 , 1993;2:117-27.

3. Hollister MC, Weintraub JA. The association of oral status with systemic health, quality of life, and economic productivity. J Dent Educ. 1993;57: 901-12.

4. Ashley ET, Covington LL, Bishop BG, Breault LG. Ailing and failing endosseous dental implants: a literature review. J Contemp Dent Pract. 2003;15:35-50

5. Sorrentino R, Gherlone EF, Calesini G, Zarone F. Effect of implant angulation, connection length, and impression material on the dimensional accuracy of implant impressions: an in vitro comparative study. Clin Implant Dent Relat Res. 2010;12(Suppl 1):e63-76.

6. Lee H, Ercoli C, Funkenbusch PD, Feng C. Effect of subgingival depth of implant placement on the dimensional accuracy of the implant impression: an in vitro study. J Prosthet Dent. 2008;99:107-13.

7. Baig MR. Multi-unit implant impression accuracy: a review of the literature. Quintessence Int. 2014;45:39-51.

8. Osman MS, Ziada HM, Abubakr NH, Suliman AM. Implant impression accuracy of parallel and non-parallel implants: a comparative in-vitro analysis of open and closed tray techniques. Int J Implant Dent. 2019;19(5): 2-10. https://doi.org/10.1186/s40729-019-0159-5.

9. Stimmelmayr M, Guth JF, Erdelt K, Happe A, Schlee M, Beuer F. Clinical study evaluating the discrepancy of two different impression techniques of four implants in an edentulous jaw. Clin Oral Investig. 2013;17:1929-35.

10. SA. New classification of physical status. Anesthesiology. 1963;24:111.D.G.

11. Atsumi M, Park SH, Wang HL. Methods used to assess implant stability: current status. Int J Oral Maxillofac Implants. 2007;22:743-54.

12. Martin W, Lewis E, Nicol A. Local risk factors for implant therapy. Int J Oral Maxillofac Implants. 2009;24(Suppl):28-38.

13. Sethi $A$, Kaus $T$, Sochor $P$. The use of angulated abutments in implant dentistry: five-year clinical results of an ongoing prospective study. Int J Oral Maxillofac Implants. 2000;15:801-10.

14. Lee SJ, Gallucci GO. Digital vs. conventional implant impressions: efficiency outcomes. Clin Oral Implants Res. 2013;24:111-5.

15. Kan JY, Rungcharassaeng K, Bohsali K, Goodacre CJ, Lang BR. Clinical methods for evaluating implant framework fit. J Prosthet Dent. 1999;81:7-13.

16. Rutkunas $\mathrm{V}$, Ignatovic J. A technique to splint and verify the accuracy of implant impression copings with light-polymerizing acrylic resin. J Prosthet Dent. 2014;111:254-6.

17. Vigolo P, Millstein PL. Evaluation of master cast techniques for multiple abutment implant prostheses. Int J Oral Maxillofac Implants. 1993;8:439-46.

18. Wadhwa SS, Mehta R, Duggal N, Vasudeva K. The effect of pouring time on the dimensional accuracy of casts made from different irreversible hydrocolloid impression materials. Contemp Clin Dent. 2013:4:313-8.

19. Papaspyridakos P, Benic Gl, Hogsett VL, White GS, Lal K, Gallucci GO Accuracy of implant casts generated with splinted and non-splinted impression techniques for edentulous patients: an optical scanning study. Clin Oral Implants Res. 2012;23:676-81.

20. Bartlett DW, Greenwood R, Howe L. The suitability of head-of-implant and conventional abutment impression techniques for implant-retained three unit bridges: an in vitro study. Eur J Prosthodont Restor Dent. 2002;10:163-6.
21. Schmidt A, Häussling T, Rehmann P, Schaaf H, Wöstmann B. Accuracy of various impression materials and methods for two implant systems: an effect size study. J Prosthodont Res. 2018;62:245-51.

22. Papaspyridakos P, Chen CJ, Gallucci GO, Doukoudakis A, Weber HP, Chronopoulos V. Accuracy of implant impressions for partially and completely edentulous patients: a systematic review. Int J Oral Maxillofac Implants. 2014;29:836-45.

23. Baig MR. Accuracy of impressions of multiple implants in the edentulous arch: a systematic review. Int J Oral Maxillofac Implants. 2014;29:869-80.

24. Gallucci GO, Papaspyridakos P, Ashy LM, Kim GE, Brady NJ, Weber HP. Clinical accuracy outcomes of closed-tray and open-tray implant impression techniques for partially edentulous patients. Int J Prosthodont. 2011;24:469-72.

25. Alikhasi M, Alsharbaty MHM, Moharrami M. Digital implant impression technique accuracy: a systematic review. Implant Dent. 2017;26:929-35.

26. Papaspyridakos P, Lal K, White GS, Weber HP, Gallucci GO. Effect of splinted and nonsplinted impression techniques on the accuracy of fit of fixed implant prostheses in edentulous patients: a comparative study. Int J Oral Maxillofac Implant. 2011;26:1267-72.

27. Kim S, Nicholls $\mathrm{Jl}$, Han CH, Lee KW. Displacement of implant components from impressions to definitive casts. Int J Oral Maxillofac Implants. 2006;21:747-55.

28. Papaspyridakos P, Hirayama $\mathrm{H}$, Chen $\mathrm{CJ}, \mathrm{Ho} \mathrm{CH}$, Chronopoulos V, Weber HP. Full-arch implant fixed prostheses: a comparative study on the effect of connection type and impression technique on accuracy of fit. Clin Oral Implants Res. 2016;27:1099-105.

29. Presotto AG, Bhering CL, Mesquita MF, Barao VA. Marginal fit and photoelastic stress analysis of CAD-CAM and overcast 3-unit implantsupported frameworks. J Prosthet Dent. 2017;117:373-9.

\section{Publisher's Note}

Springer Nature remains neutral with regard to jurisdictional claims in published maps and institutional affiliations.

\section{Submit your manuscript to a SpringerOpen ${ }^{\circ}$ journal and benefit from:}

- Convenient online submission

- Rigorous peer review

- Open access: articles freely available online

High visibility within the field

- Retaining the copyright to your article

Submit your next manuscript at $\boldsymbol{\nabla}$ springeropen.com 